\title{
Resonant response of a Hodgkin-Huxley neuron to a spike train input
}

\author{
Lech S Borkowski
}

Address: Quantum Physics Division, Faculty of Physics, Adam Mickiewicz University, 61-614 Poznan, Poland

Email: Lech S Borkowski - lsb@amu.edu.pl

from Eighteenth Annual Computational Neuroscience Meeting: CNS*2009

Berlin, Germany. 18-23 July 2009

Published: 13 July 2009

BMC Neuroscience 2009, I0(Suppl I):P250 doi:10.II86/I47|-2202-I0-SI-P250

This abstract is available from: http://www.biomedcentral.com/I47I-2202/I0/SI/P250

(c) 2009 Borkowski; licensee BioMed Central Ltd.

\section{Introduction}

Experiments show that neurons have a tendency to respond to signals tuned to a resonant frequency [1]. In order to understand the general properties of a resonant response of a neuron, we study the silent Hodgkin-Huxley neuron driven by periodic input. The current arriving through the synapse consists of a set of spikes $I_{p}(t) \sim \mathrm{g}_{\text {syn }}$ $\Sigma(\mathrm{t} / \tau) \exp (-t / \tau) C(t)\left(V_{a}-V_{\text {syn }}\right)$, where $g_{\text {syn }}$ is the synapse conductivity, $\tau$ is the time constant associated with the synapse conduction, $V_{a}$ is the maximum membrane potential and $V_{\text {syn }}$ is the reversal potential of the synapse.

\section{Results}

See Figures 1 and 2.

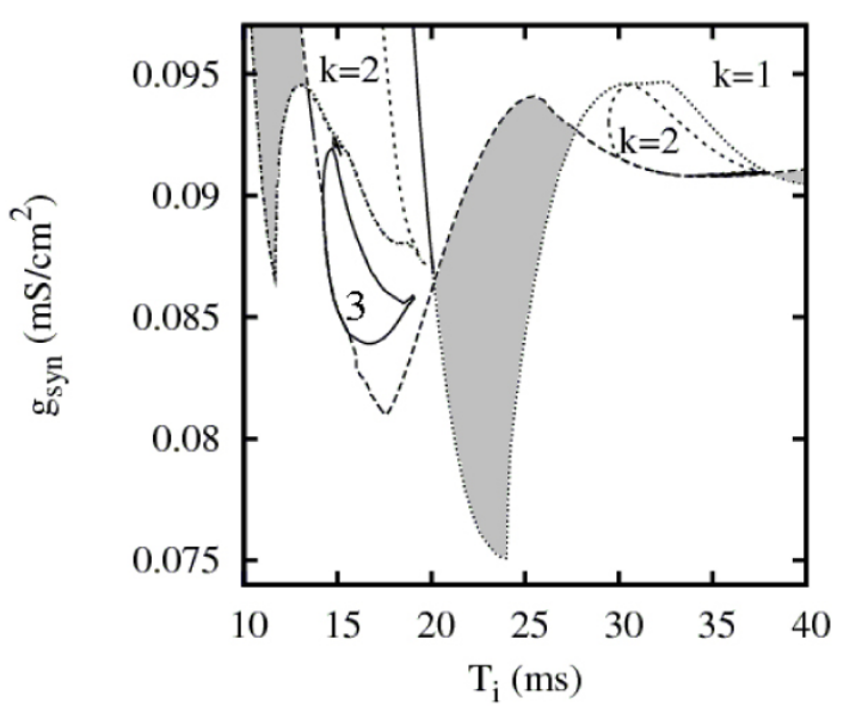

Figure I

The phase diagram for typical HH model parameters [2] in the limit of small synaptic conductivity. There is a well-pronounced minimum at $T_{i}=17.5 \mathrm{~ms}$. The resonant nature of the response can be seen also at multiples of this value, at $T_{i} \approx 34 \mathrm{~ms}$ and $T_{i} \approx 50 \mathrm{~ms}$. Near the resonance the system has the tendency to mode locking with high values of $k$, where $k=T_{o} / T_{i}$ is the ratio of the output ISI to the input ISI. For example near the main resonance frequency we find narrow regions with $k=5,6$ or 9 . Areas with bistable solutions are shown in grey. We expect the resonance at $T_{i}=$ I7.5 ms to survive in the presence of noise. 


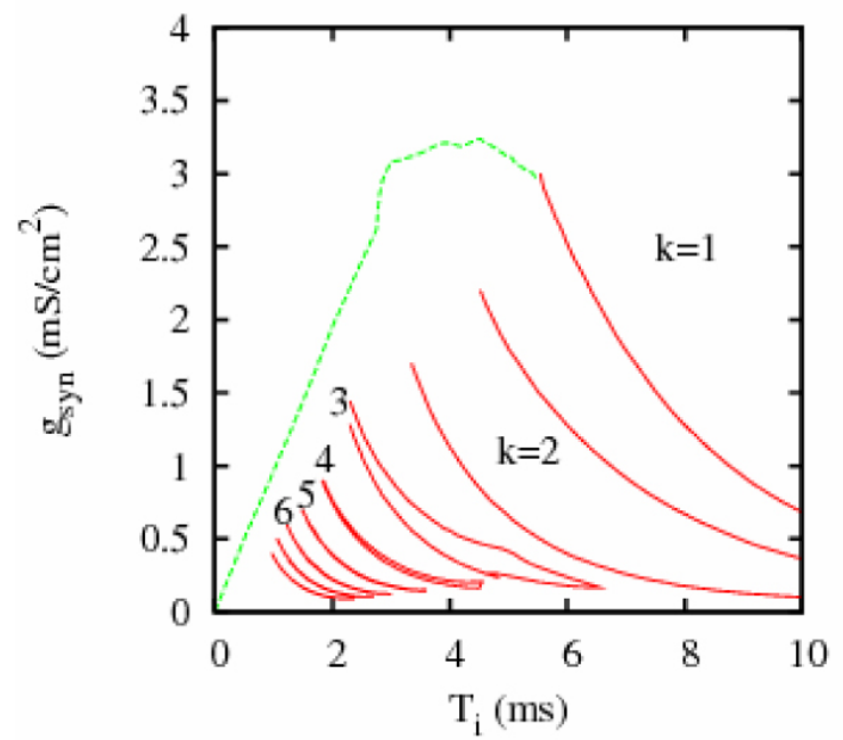

Figure 2

In the limit of small $T_{i}$ the distinction between the firing spikes and subthreshold oscillations disappears and the output signal decreases to 0 for sufficiently large $\mathbf{g}_{\text {syn }}$. Broken line in the figure indicates a transition to nonfiring behavior. In the area below this transition the amplitude of the spikes gradually increases. Solid lines are borders of the mode-locked states with different values of $k$. Properties of this model are similar to the $\mathrm{HH}$ model with a sinusoidal driving current at intermediate values of input ISI $T_{i}$ $=5-12 \mathrm{~ms}$. However the results in both the high and the low frequency regime are qualitatively different. In the case of a sinusoidal input there is only one resonance frequency and reported values of $k$ are lower [3].

\section{Acknowledgements}

Part of the numerical computation was performed in the Computer Center of the Tri-city Academic Computer Network in Gdansk, Poland.

\section{References}

I. Hutcheon B, Yarom Y: Resonance, oscillation and the intrinsic frequency preference of neurons. Trends Neurosci 2000, 23:216-222.

2. Hasegawa $\mathrm{H}$ : Responses of a Hodgkin-Huxley neuron to various types of spike-train inputs. Phys Rev E 2000, 61:718-726.

3. Lee SG, Kim S: Bifurcation analysis of mode-locking structure in a Hodgkin-Huxley neuron under sinusoidal current. Phys Rev E 2006, 73:04I924.
Publish with Bio Med Central and every scientist can read your work free of charge

"BioMed Central will be the most significant development for disseminating the results of biomedical research in our lifetime. "

Sir Paul Nurse, Cancer Research UK

Your research papers will be:

- available free of charge to the entire biomedical community

- peer reviewed and published immediately upon acceptance

- cited in PubMed and archived on PubMed Central

- yours - you keep the copyright 